\title{
Inequality aversion, social discount, and time discount rates
}

\section{Takanori Ida}

Graduate School of Economics, Kyoto University

Yoshida, Sakyo, Kyoto 606-8501, Japan

ida@econ.kyoto-u.ac.jp

\section{Kazuhito Ogawa}

Faculty of Sociology, Kansai University

3-3-35 Yamate-cho, Suita-shi, Osaka 564-8680 Japan

ogawa.kazuhito@gmail.com

\begin{abstract}
Purpose - We conduct a hypothetical dictator game with social distance and time delays using conjoint analysis.

Design / methodology / approach - Responses from 1,347 Japanese adults are collected through an online survey, and their responses are analyzed using a random parameter logit model.

Findings - Social preference for the present income of a stranger equals social preference for the income of an acquaintance 140 days later, of a close friend 224 days later, and of a family member 255 days later.
\end{abstract}

Originality / value- We simultaneously estimate social preference parameters including the inequality aversion rate, the social discount rate, and the time discount rate Headings - Inequality aversion, social discount, and time discount Keywords - dictator game, inequality aversion, social discounting, time discounting Paper type - Research paper 


\title{
Inequality aversion, social discount, and time discount rates
}

\author{
Abstract \\ Purpose - We conduct a hypothetical dictator game with social distance and time delays \\ using conjoint analysis. \\ Design / methodology / approach - Responses from 1,347 Japanese adults are \\ collected through an online survey, and their responses are analyzed using a random \\ parameter logit model. \\ Findings - Social preference for the present income of a stranger equals social \\ preference for the income of an acquaintance 140 days later, of a close friend 224 days \\ later, and of a family member 255 days later.
}

Originality / value- We simultaneously estimate social preference parameters including the inequality aversion rate, the social discount rate, and the time discount rate Headings - Inequality aversion, social discount, and time discount Keywords - dictator game, inequality aversion, social discounting, time discounting Paper type - Research paper 


\section{Introduction}

Economists have long assumed that homo economicus is only concerned with its own payoff. However, with the development of behavioral economics, economists have come to understand that altruism cannot be completely excluded either from laboratories or from an understanding of the real economy. A good example that shows the existence of altruism is a comparison between ultimatum and dictator game experiments. Ultimatum games involve a giver or dictator (D) and a recipient (R); a certain sum of money is the value of the gain from exchange that would be lost if $R$ rejects the offer. D offers share $s$ to R, leaving himself with the remainder, 1-s. R can either accept the offer or reject it, in which case both receive nothing. The previous literature found that most offers are between 0.4 and 0.5 of the surplus; there are almost no offers below 0.2 , and the low offers are frequently rejected. Dictator games are different from ultimatum games because R's ability to reject an offer is removed. The first comprehensive surveys of both games (such as Forsythe et al. 1994) indicated that D offers on average about $20 \%$, which is much lower than the figure in ultimatum games but still remains positive.

Behavioral economics has recently investigated social preferences as well as time and risk preferences. Fehr and Schmidt (1999) modeled fairness as self-centered inequality aversion. In the inequality aversion model, one's utility is determined by one's own payoff and by distributive inequality: the larger the inequality between oneself and the opponent is, the lower one's utility is. Concurrently with inequality aversion research, social discounting research has been accumulated (Jones and Rachlin 2006, 2009). In this literature, social distance is defined as the degree of reciprocity that subjects believe exists within a social interaction. The social distance, therefore, indicates how close subjects (friends, friends of friends, and so on) are to each other. Altruistic behavior decreases with social distance, which is predicted by the inverse distance law of giving (see Goeree et al. 2010). Much research has been conducted based on the following factors and procedures:

- "earned" right to become the dictator (Hoffman et al. 1994)

- double and single blind procedures (Hoffman et al. 1996)

- silent identification and face-to-face communication (Bohnet and Frey 1999) 
- complete double blind procedure (Johannesson and Persson 2000)

- picture viewing procedure (Burnham 2003)

- poverty and medicine instead of money (Brañas-Garza 2006)

- degree of anonymity and gender (Dufwenberg and Muren 2006)

- opportunity to make a request (Rankin 2006)

- family name of recipient (Charness and Gneezy 2008)

- request and communication effects (Yamamori et al. 2008)

- gender and expectations (Aguiar et al. 2009)

- directed altruism and future interaction (Leider et al. 2009)

- friendship networks (Goeree et al. 2010)

- social integration (Brañas-Garza et al. 2010)

Note that although inequality aversion and social discounting are both social preferences, they are clearly differentiated. The results of dictator games indicate that $\mathrm{D}$ offers a certain share even to a stranger. Such altruism can be explained by inequality aversion. Interestingly, the share that $\mathrm{D}$ offers to $\mathrm{R}$ increases if $\mathrm{R}$ is no longer a stranger but an acquaintance. This phenomenon can be explained by social discounting. This paper proposes a method for simultaneously estimating the inequality aversion rate and the social discount rate.

In addition, this paper integrates the time discount rate estimation with the simultaneous estimation of the inequality aversion rate and the social discount rate. ${ }^{1}$ Some previous studies have simultaneously investigated time and social discounting (Rachlin and Jones 2008a). This paper is the first to explicitly measure the inequality aversion rate, the time discount rate, and the social discount rate in the inequality aversion model. We conducted dictator game experiments with social distance and time delays using conjoint analysis. Responses from 1,347 Japanese adults were collected through online surveys, and their responses were analyzed using a random parameter logit model.

We obtained the following results. First, the marginal utility derived from one's own

\footnotetext{
${ }^{1}$ However, this paper is not concerned with risk preference estimation. Interestingly, Carlsson et al. (2005) found that inequality aversion is positively associated with risk aversion.
} 
income is twice as large as the marginal utility derived from inequality aversion. This means that one will be better off if the change in one's own income is more than half of the change in inequality. Second, social preferences for a stranger's present income equal social preferences for the income of an acquaintance 140 days later, of a close friend 224 days later, and of a family member 255 days later. Third, these social preference parameters are correlated with each other as well as with individual characteristics such as gender and age.

The paper is organized as follows. Section 2 explains the survey design. Section 3 formalizes our dictator game, which considers both social and time discounting in its conjoint analysis. Section 4 displays the estimation results for the substitution between own income and social preferences and between the social preferences. Section 5 provides concluding remarks.

\section{Survey and Data}

\subsection{Various dictator game experiments}

This section explains the survey we used to investigate the social preferences of respondents based on their replies to a standard dictator game. We presented the following scenario:

\section{Scenario 1}

You have joined a psychological experiment. You are given 100,000 JPY (1,200 US\$, given $85 \mathrm{JPY}=1 \mathrm{US} \$$ ) and are told that you can share the money with Person A. You are not acquainted with $\mathrm{A}$ and will not meet A during the experiment or in the future. A does not know you. A cannot refuse your proposal. How much money will you give to $\mathrm{A}$ ?

Next, we changed the social distance of Person A and investigated how this influenced the answer.

\section{Scenario 2}

Previously, Person A was assumed to be a stranger. Now your relationship with A 
has changed, and you are asked the same question. Person A is:

- A same-sex acquaintance with whom you associate closely

- A same-sex friend with whom you dine

- A same-sex blood relative (family member)

Assume you have such relationships with people.

Lastly, we changed the time delay determining when Person A received his share and investigated how this influenced the answer.

Previously, Person A was assumed to immediately receive the money. The time delay in which A receives the money has been changed to the following, and you are asked the same question:

- One day later

- One month later

- One year later

- Ten years later

You can receive your share of the money right now.

\subsection{Respondent characteristics}

The experiment survey was conducted in July 2010 by an Internet investigative company. The total number of registered subjects exceeded 300,000, and their composition represented Japanese demographic characteristics very well. The respondents were selected from Japanese adults. Since explicit strategic interactions do not exist in dictator games, we could carry out the game online; perfect double blindness could be maintained, and many responses could be collected in a very short period of time. On the other hand, some framing effects are unavoidable, because online surveys may have different psychological impacts on respondents' answers; we must analyze the answers carefully.

Note that respondents who replied to the conjoint questionnaire received 500 JPY (7 US\$). Respondents who replied in an unrealistically short period of time were excluded. Previous studies pointed out that incentive structure influences the response results (Sefton 1992, Forsythe et al. 1994). Recent research has indicated, however, that the 
presence or absence of an incentive is unrelated to the outcomes observed in dictator games (Ben-Nera et al. 2008, Engel 2010).

The following are the individual characteristics of the 1,347 respondents. Six hundred fifty-eight (48.8\%) were male, and $689(51.1 \%)$ were female. The average age was 40.65. Five hundred thirty-one (39.4\%) were unmarried, and $816(60.6 \%)$ were married. Six hundred fifty-three (48.5\%) had children; the average number of children was 2.5. Furthermore, $640(47.5 \%)$ were university graduates, and $701(52.0 \%)$ had full-time jobs. The average household income of the respondents was 5.7 million JPY $(67,000$ US\$). The above figures are close to the averages for all Japanese adults.

Note that previous experiments were limited; they had small sample sizes and biased sample compositions (e.g., some samples were composed solely of university students). In contrast, this study has the advantage of a large sample that is composed of individuals with diverse characteristics.

\subsection{Dictator game with social discounting}

Next we present the survey results of a dictator game with social discounting. We asked respondents about social distances to derive social discount rates. As was explained above, social distance is defined as the degree of reciprocity that respondents believe exists within social interactions. Social distance, therefore, indicates the closeness of subjects: friends, friends of a friend, acquaintances, etc.

Jones and Rachlin (2006) measured social distance by asking respondents to rank 100 people by ordinal numbers. In contrast, our survey allows respondents to directly determine the social distances for strangers, acquaintances, friends, and family members. One advantage of our method is that we can measure social discount rates over social distances expressed as cardinal numbers.

Setting the distance to oneself as 0 units and the distance to perfect strangers as 100 units, we asked about social distances for same-sex acquaintances, same-sex friends, and same-sex family members. The means and standard deviations of the social distances given in the replies are summarized as follows.

Mean S.D. 


$\begin{array}{ccc}\text { Acquaintance } & 63.90 & 25.37 \\ \text { Friend } & 42.51 & 23.91 \\ \text { Family member } & 34.55 & 31.62\end{array}$

The survey results of the dictator game vary according to social distance. The results include the average offer rate, the proportion of zero offers, and the proportion of equal offers.

$\begin{array}{cccc} & \text { Average offer rate } & \begin{array}{c}\text { Zero offer } \\ \text { proportion }\end{array} & \begin{array}{c}\text { Equal offer } \\ \text { proportion }\end{array} \\ \text { Stranger } & 31.8 \% & 21.3 \% & 49.1 \% \\ \text { Acquaintance } & 34.5 \% & 14.8 \% & 53.5 \% \\ \text { Friend } & 40.4 \% & 7.2 \% & 65.9 \% \\ \text { Family member } & 43.8 \% & 6.0 \% & 70.5 \%\end{array}$

Social discounting is defined as one's ability to make choices in accordance with the interests of a relatively large social group with which one shares interests. Hamilton's kin-selection theory argues that altruism is greater if there is more generic overlap (a higher degree of kinship). Rachlin and Jones (2008b) argued that kinship can be identified in terms of social distance; the closer one feels to someone else, the greater one's generic overlap with that person is likely to be and the more altruistic one is expected to be toward him/her.

The survey results are as expected. The offer rate is the highest (respondents are the most altruistic) for a same-sex family member whose social distance from the respondent is the smallest, and the rate is also fairly large for a same-sex friend whose social distance from the respondent is small. However, the rate is the smallest (respondents are the least altruistic) for a same-sex stranger whose social distance from the respondent is the largest.

Fig. 1 depicts the relationship between the three distributive indexes and social distance. An increase in social distance leads to a decrease in the offer rate, an increase in the proportion of zero offers, and a decrease in the proportion of equal offers.

$<$ Fig. $1>$ 
2.4 Dictator game with time discounting

We next present the survey results of the dictator game with time discounting. Assuming that $\mathrm{R}$ is a stranger whose receipt of the money is delayed, we conducted the dictator game by changing the time of receipt from the same day to one day later, one month later, one year later, and ten years later.

The survey results of the dictator game vary depending on the time delay and include the average offer rate, the proportion of zero offers, and the proportion of equal offers.

$\begin{array}{cccc} & \text { Average offer rate } & \begin{array}{c}\text { Zero offer } \\ \text { proportion }\end{array} & \begin{array}{c}\text { Equal offer } \\ \text { proportion }\end{array} \\ \text { Today } & 31.8 \% & 21.3 \% & 49.1 \% \\ \text { One day } & 28.2 \% & 28.1 \% & 43.3 \% \\ \text { One month } & 27.0 \% & 29.8 \% & 40.4 \% \\ \text { One year } & 24.6 \% & 36.5 \% & 36.4 \% \\ \text { Ten years } & 21.7 \% & 45.8 \% & 33.9 \%\end{array}$

We assume that one's own payoff is received promptly, while R's payoff is delayed. Therefore, the discounted present value of R's payoff decreases as the time delay for $\mathrm{R}$ increases. The survey results are as expected. The offer rate is the highest (respondents are the most altruistic) when the money is given to $\mathrm{R}$ promptly, and the rate is the lowest (respondents are the least altruistic) in the case of a ten-year delay.

\subsection{Summary}

We summarize the findings that have been obtained so far. First, the average offer rate was $31.8 \%$ for the normal dictator game, which slightly exceeded the predictions in the previous research (20-30\%).

This result may reflect the cultural differences between Japan and Western countries. Japanese culture is often described as homogeneous and cooperative. Previous literature has observed that patterns of altruism in Japan are different from patterns of altruism in Western countries (Roth et al. 1991, Buchan et al. 1997). 
Another possible reason for this result is that the average age of the respondents was 40.65 and the sample included some senior citizens. The offer rate could be higher because age is positively associated with inequality aversion, which we will examine later. Note that this survey was double blind, and uniform compensation was paid to the respondents. Recent research has indicated that the impact of an incentive on D's generosity is more complicated than was previously thought and that it varies across individuals (Ben-Nera 2008, Engel 2010). Future research will investigate how incentive structure influences survey results.

Many studies have found that altruism is inversely proportional to social distance (Goeree et al. 2010). This paper obtained results that are similar to those obtained in previous research.

Lastly, although few studies have measured the time discount rate in dictator games, Rachlin and Jones (2008a) investigated a setting in which the payoff was delayed for D, while the payoff was promptly given to R. Kovarik (2008) also measured time discount rates when payoffs were delayed for both $\mathrm{D}$ and $\mathrm{R}$. It follows from their results that self-concerned fairness may be discounted at different rates. We approach time discounting from a different angle and assume that one's own payoff is realized now, while the opponent's payoff is delayed. Therefore, our time discount rate can be characterized as a social preference.

\section{Dictator Game with Social Discounting and Time Discounting}

\subsection{Conjoint analysis}

Previous research has dealt separately with social and time discounting in dictator games. This paper proposes a new method to simultaneously measure the rates of three social preferences: inequality aversion, social discounting, and time discounting.

Conjoint analysis assumes that each alternative is a profile composed of attributes. If we include too many attributes and levels, respondents find it difficult to answer the questions. On the other hand, if we do not include enough attributes and levels, the description of the alternatives is inadequate. After conducting several pretests, we decided on the following alternatives, attributes, and levels. 
D divides 100,000 JPN (1,200 US\$) with R.

$\mathrm{R}$ is a stranger, a same-sex acquaintance, a same-sex close friend, or a same-sex family member.

The time delay for R's payoff is zero, one day, one month, or one year.

The number of profiles becomes unmanageable if all possible combinations are considered; we avoid this problem by adopting an orthogonal planning method. Fig. 2 depicts a representative questionnaire. We posed sixteen questions to each respondent. Therefore, the total number of answers was $1,347 * 16=21,552$.

$<$ Fig. $2>$

\subsection{Development of the inequality aversion model}

A well-known model that describes social preferences is the inequality aversion model; this section develops such a model to address three social preferences: inequality aversion, social discounting, and time discounting.

Fehr and Schmidt (1999) modeled the social preference of inequality aversion, which means the degree to which people resist inequitable outcomes. Formally, consider two players, indexed $D$ and $R$, and let $x=\left(x_{D}, x_{R}\right)$ denote the vector of monetary payoffs ${ }^{2}$. The utility function of player $D$ is given by

$$
U_{D}=x_{D}-\alpha_{1} \times \max \left(x_{D}-x_{R}, 0\right)-\alpha_{2} \times \max \left(x_{R}-x_{D}, 0\right) .
$$

Parameters $\alpha_{1}$ and $\alpha_{2}$ denote inequality aversion and envy respectively. Note that we focus on $\alpha_{1}$ because $x_{D}-x_{R} \geq 0$ is normal in dictator games.

It is usually assumed that the utility function is linear in inequality aversion. The inequality aversion model predicts, therefore, that the dictator makes a fifty-fifty offer if

\footnotetext{
${ }^{2}$ Alternatively, we can regard altruism from a status-based motivation. Wichardt (2009) discussed that behavior was driven from membership in a successful group as well as individual success. It must be noted here that other-regarding preference cannot be incorporated into welfare economics because the constrained maximization result is undefined if the individual utility depends on the other one (Gowdy and Polimeni 2005).
} 
$\alpha_{1}>0.5$ and a zero offer if $\alpha_{1}<0.5$. The linearity assumption is imposed to keep the model as simple as possible. However, experimental results such as those of Forsythe et al. (1994) have shown that the average offer is around $20 \%$; only $20 \%$ of dictators choose zero offers, and $20 \%$ choose fifty-fifty offers. If we allow for a concave utility function, the optimal offers are in the interior of [0, 0.5]. For example, Kovarik (2008) adopted a standard Cobb-Douglas utility function on this ground. ${ }^{3}$

In this paper, we postulate that social preference is determined by distributive inequality, social distance, and time delay. We thus assume that an increase in inequality (denoted by $q_{R}=x_{D}-x_{R}$ ) causes a decrease in utility as a result of inequality aversion. We denote the inequality aversion rate by $\alpha$. Next we assume that an increase in social distance (denoted by $s_{R}$ ) leads to a decrease in utility because the dictator has less concern for the opponent. We denote the social discount rate by $\beta$. Finally, we assume that an increase in the time delay (denoted by $t_{R}$ ) causes a decrease in utility as a result of discounting the opponent's value. We denote the time discount rate by $\gamma$. In summary, we model the social preference: ${ }^{4}$

$$
q_{R}^{-\alpha} \times \exp \left(-\beta \times s_{R}\right) \times \exp \left(-\gamma \times t_{R}\right),
$$

and obtain the following using logarithms: ${ }^{5}$

$$
-\alpha \times \ln q_{R}-\beta \times s_{R}-\gamma \times t_{R} .
$$

The random utility that $\mathrm{D}$ obtains from choosing alternative $i$ can be expressed in this inequality aversion model as follows:

$$
U_{D i}=\ln x_{D i}-\alpha \times \ln q_{R i}-\beta \times s_{R i}-\gamma \times t_{R i}+\varepsilon_{D i},
$$

where $\varepsilon_{D i}$ denotes an independently and identically distributed extreme value (IIDEV) term. Note that we have assumed that own utility is the $\log$ of own payoff $\left(\ln x_{D i}\right)$ and

${ }^{3}$ See also Bolton and Ockenfels (2000) for an alternative model.

${ }^{4}$ Some previous models adopted a hyperbolic form instead of an exponential form (Jones and Rachlin 2009). Hyperbolic models can be compatible with exponential models by a simple transformation of variables. For example, if psychological time is set as a logarithm of physical time, an exponential discounted model with respect to physical time can be transformed into a hyperbolic discounted model with respect to psychological time (Takahashi 2005).

${ }^{5}$ In the case of a fifty-fifty offer $\left(q_{R}=0\right)$, we cannot define $\ln q_{R}$ and instead estimate $\ln \left(1+q_{R}\right)$. 
have normalized its coefficient to 1 .

\subsection{Random parameter logit model}

Conditional logit (CL) models, which assume independent and identical distributions (IID) of random terms, have been widely used in previous studies. However, the independence from irrelevant alternatives (IIA) property derived from the IID assumption of the CL model is too strict to allow for flexible substitution patterns. The most prominent example is a random parameter logit (RPL) model that can accommodate differences in the variance of random components.

Assuming that parameters are distributed with density function $f(\alpha, \beta, \gamma)$ (Train 2003, Louviere et al. 2000), the RPL specification allows for repeated choices by each sampled decision maker in such a way that the coefficients vary over people but are constant over choice situations for each person. The logit probability of decision maker $n$ choosing alternative $i$ in choice situation $t$ is expressed as

$$
L_{n i}(\alpha, \beta, \gamma)=\exp \left(V_{n i}(\alpha, \beta, \gamma)\right) / \sum_{m=1}^{N} \exp \left(V_{m i}(\alpha, \beta, \gamma)\right) \text {, }
$$

which is the product of normal logit formulas, the observable portion of utility function $V_{n i t}$, and alternatives $n=1, \ldots, N$. Therefore, RPL choice probability is a weighted average of logit probability $L_{n i}$ with density function $f(\alpha, \beta, \gamma)$, which can be written as

$$
P_{n i}=\iiint\left(\exp \left(V_{n i}(\alpha, \beta, \gamma)\right) / \sum_{m=1}^{N} \exp \left(V_{m i}(\alpha, \beta, \gamma)\right)\right) f(\alpha, \beta, \gamma) d \alpha d \beta d \gamma
$$

We assume hereafter that $f(\alpha, \beta, \gamma)$ follows multivariate normal distributions.

Because the RPL choice probability is not expressed in closed form, simulations need to be performed for the RPL model estimation. RPL choice probability is approximated through a simulation method. We can also calculate the estimator of the conditional mean of the random parameters $h\left(\alpha, \beta, \gamma \mid y_{i}\right)$, conditioned on individual specific choice profile $y_{n}$, given as

$$
h\left(\alpha, \beta, \gamma \mid y_{i}\right)=\left(P\left(y_{i} \mid \alpha, \beta, \gamma\right) f(\alpha, \beta, \gamma)\right) /\left(\iiint P\left(y_{i} \mid \alpha, \beta, \gamma\right) f(\alpha, \beta, \gamma) d \alpha d \beta d \gamma\right) \text {. }
$$

Accordingly, we can demonstrate variety in the parameters at the individual level with the maximum simulated likelihood (MSL) method of estimation using 100 Halton 
draws. ${ }^{6}$ Furthermore, since a respondent repeatedly completes sixteen questionnaires in the conjoint analysis, the data form a panel, and we can also apply a standard random effect estimation.

\subsection{Estimation results}

Our estimation results are shown in Table 1. Since we assumed that $f(\alpha, \beta, \gamma)$ followed a multivariate normal distribution, the estimates and the standard errors are reported for the parameter's mean and standard deviation, respectively. All estimates have the expected signs, and their $t$ values are all statistically significant at the $1 \%$ level.

$<$ Table 1 $>$

From the estimates of the social discount rate $(\beta=0.0132)$ and the time discount rate $(\gamma=0.0034)$, we can calculate the weights attached to the social distances and the time delays. First, on the basis of $\operatorname{Exp}\left(-0.0132 \times s_{R}\right)$, the following weights are given for strangers, acquaintances, friends, and family members.

$\begin{array}{cc}\text { Social distance } & \text { Weight } \\ \text { Stranger } & 0.27 \\ \text { Acquaintance } & 0.43 \\ \text { Friend } & 0.57 \\ \text { Family member } & 0.63\end{array}$

Next, on the basis of Exp $\left(-0.0034 \times t_{R}\right)$, the following weights are given for delays of one day, one month, and one year.

${ }^{6}$ Louviere et al. (2000, p. 201) suggested that 100 replications are normally sufficient for a typical problem involving five alternatives, 1,000 observations, and up to ten attributes. The adoption of the Halton sequence draw is an important problem to be examined (Halton 1960). Bhat (2001) found that 100 Halton sequence draws are more efficient than 1,000 random draws for simulating an RPL model. 
Time delay

One year

One month

One day
Weight

0.289

0.902

0.997

\section{Analysis Results}

4.1 Substitutability between own income and social preference terms

This paper formalized that utility is dependent on own income and social preference terms and that the latter depends on distributive inequality, social distance, and time delay. At this point, we examine the marginal rate of substitution (MRS) between own income and the social preference terms.

Result 1: MRS between own income and distributive inequality

The MRS between own income (log) and distributive inequality (log) is $\alpha=0.445$.

This means that a $1 \%$ increase in inequality is compensated by a $0.445 \%$ increase in own income to hold utility constant. Correspondingly, a $1 \%$ increase in own income is compensated by a $2.247 \%$ increase in inequality.

Result 2: MRS between own income and social distance

The MRS between own income (log) and social distance is $\beta=0.013$. This means that a 1-unit increase in social distance is compensated by a $1.3 \%$ increase in own income to hold utility constant. Correspondingly, a 1\% increase in own income is compensated by a 0.77-unit increase in social distance.

Result 3: MRS between own income and time delay

The MRS between own income (log) and the time delay is $\gamma=0.003$. This means that a 1-day increase in the time delay is compensated by a $0.3 \%$ increase in own income to hold utility constant. Correspondingly, a 1\% increase in own income is compensated by a 3.33-day increase in the time delay.

The tradeoff between economic growth and distribution has been an important issue 
in macroeconomics (Rotemberg 2008). In Japan, because income disparities can no longer be ignored, the degree of substitutability between own income and inequality must be investigated at the individual level.

The most interesting finding is Result 1 . The inequality aversion model assumes that the inequality aversion parameter is less than the coefficient of own income $(\alpha<1)$. We obtain a reasonable result when the coefficient of own income is twice the inequality aversion parameter ( $\alpha=0.445$ ). We conclude that utility will increase if the increase in own income is more than half the increase in inequality.

Result 2 shows that a $1.3 \%$ change in own income is indifferent to a 1-unit change in the opponent's social distance. For example, the distance between an acquaintance and a friend is 21 units; therefore, a change that replaces an acquaintance for a friend as the opponent is compensated by a $28 \%$ decrease in own income. In addition, Result 3 shows that a $0.3 \%$ change in own income is indifferent to a 1-day delay of opponent's receipt. Therefore, a delay of the opponent's receipt by one month is compensated by a $9 \%$ increase in own income.

4.2 Substitutability between social preference terms

Next we examine MRS between the social preference terms: distributive inequality, social distance, and the time delay.

Result 4: MRS between distributive inequality and social distance

The MRS between inequality (log) and social distance is $\beta / \alpha=0.03$. This means that a 1-unit increase in social distance is compensated by a 3\% decrease in inequality to hold utility constant. Correspondingly, a $1 \%$ increase in inequality is compensated by a 0.33-unit decrease in social distance.

Result 5: MRS between distributive inequality and time delay

The MRS between inequality (log) and the time delay is $\gamma / \alpha=0.008$. This means that a 1-day delay in the opponent's receipt is compensated by a $0.8 \%$ decrease in inequality to hold utility constant. Correspondingly, a 1\% decrease in inequality is compensated by a delay of the opponent's receipt by 1.25 days. 


\section{Result 6: MRS between social distance and time delay}

The MRS between social distance and the time delay is $\beta / \gamma=3.899$. This means that a 1-unit increase in social distance is compensated by decreasing the time delay by 3.899 days to hold utility constant. In other words, a 1-day delay of the opponent's receipt is compensated by a 0.256-unit decrease in social distance.

The most interesting of these findings is Result 6 . Given that social distance to oneself is 0 units and that social distance to a stranger is 100 units, we can calculate the time delays for the receipts of acquaintances, friends, and family members that are indifferent to the immediate receipt of a stranger:

$$
\begin{aligned}
& \text { Social distance } \\
& \text { Acquaintance } \\
& \text { Friend }
\end{aligned}
$$

Family member
Time delay

$$
\begin{aligned}
& 140 \text { days }(=3.899 * 36.02) \\
& 224 \text { days }(=3.899 * 57.49) \\
& 255 \text { days }(=3.899 * 65.45)
\end{aligned}
$$

The relationships above are depicted in Fig. 3. Assuming that the MRS values are constant, the tradeoffs between the time delay and social distance for acquaintances, friends, and family members are plotted in a straight line between oneself and strangers.

$<$ Fig. 3 $>$

Result 4 shows that a 3\% change in distributive inequality is indifferent to a 1-unit change in opponent's social distance. For example, given that the distance between an acquaintance and a friend is 21 units, a change that replaces an acquaintance for a friend as the opponent is compensated by a $64 \%$ increase in equality. In addition, Result 5 shows that a $0.8 \%$ change in inequality is indifferent to a 1-day delay of opponent's receipt. Therefore, delaying the opponent's receipt by one month is compensated by a $24 \%$ decrease in inequality.

\section{Discussion}

5.1 Correlations between the social preference parameters 
In the RPL model, we can calculate the estimator of the conditional mean of the random parameters, conditioned on the individual specific choice profiles; accordingly, we investigate the correlations between the inequality aversion rate, the social discount rate, and the time discount rate at the individual level.

The coefficients of correlation are calculated and are presented in Table 2. Although the values vary in size, they are all statistically significant at the $1 \%$ level. Inequality aversion and social discount rates are negatively correlated, while inequality aversion and time discount rates are positively correlated; the social and time discount rates are positively correlated.

$<$ Table 2>

These correlations observed at the individual level suggest the existence of a systematic mechanism that generates social preferences that can be categorized into congenital and acquired characteristics. The former includes intrinsic factors such as health, age, and gender, and the latter includes income, education, marriage status, and occupation.

\subsection{Regression analysis of social preferences on individual characteristics}

We next regress the social preference parameters on individual characteristics. The explained variables are the inequality aversion rate, the social discount rate, and the time discount rate. The explanatory variables are a female dummy, age, a marriage dummy, and number of children.

The regression results are shown in Table 3. The inequality aversion rate is significantly associated with the female dummy and age; the social discount rate is not significantly associated; the time discount rate is significantly associated with the female dummy and age.

$<$ Table 3>

To summarize, the individual variables that are closely associated with social 
preferences are age and the female dummy. Note, however, that we did not address the individual characteristics at the time of the RPL estimation, given that they directly influence social preference parameters. At this point, significant correlations cannot be found between social preferences and education, income, and certain other characteristics.

\subsection{Re-estimation of the RPL model using mean-shifting parameters}

Finally, we re-estimate the RPL model using mean-shifting parameters. In particular, we consider age, a female dummy, and a marriage dummy as mean-shifting parameters.

The main results are extracted as follows:

$$
\begin{aligned}
& \text { Inequality aversion rate }(\alpha)=0.0149(0.2566)+0.1981(0.1075) \times \text { Female } \\
& +0.0100(0.0047) * \times \text { Age }-0.1670(0.1217) \times \text { Marriage } \\
& \text { Social discount rate }(\beta)=0.0150(0.0029)^{* *}-0.0005(0.0012) \times \text { Female } \\
& +0.0000(0.0000) \times \text { Age }-0.0024(0.0014) \times \text { Marriage } \\
& \text { Time discount rate }(\gamma)=0.0013(0.0004)^{* *}+0.0005(0.0002) * \times \text { Female } \\
& +0.00004(0.00001)^{* *} \times \text { Age }-0.0001(0.0002) \times \text { Marriage }
\end{aligned}
$$

Note: ${ }^{* *} \mathrm{p}<0.01,{ }^{*} \mathrm{p}<0.05$ (standard errors in parenthesis)

These results are consistent overall with the results that were obtained previously. The mean of the inequality aversion rate is positively associated with and age, while the mean of the social discount rate is not associated. The mean of the time discount rate is positively associated with the female dummy and age.

The positive correlations of the inequality aversion rate and the time discount rate with the female dummy and age were observed both in the regression analysis and in the RPL model. We conclude that social preferences are related to the individual characteristics, including gender and age. Future research will investigate the influences on social preferences of other individual characteristics, including education level, income level, and occupation.

\section{Conclusion}


This paper investigated a hypothetical dictator game that considered social discounting and time discounting in combination and that also simultaneously estimated the following social preference parameters: the inequality aversion rate, the social discount rate, and the time discount rate. First, we measured the MRS between own income and distributive inequality, between own income and social distance, and between own income and the time delay. Second, we measured the MRS between inequality and social distance, between inequality and the time delay, and between social distance and the time delay. The tradeoff between economic growth and distribution has been an important issue in macroeconomics. With the development of micro-econometrics, research on social preferences at the individual level has also been accumulated. The conclusions obtained in this paper will provide ample implications for policy discussions with respect to social preferences. However, some problems remain. For example, these results were based on particular assumptions regarding functional forms. Conducting the analysis with different functional forms will be a task for future research. 


\section{References}

Aguiar, F., Brañas-Garza, P., Jiménez, N., and Miller, L. (2009), "Are women expected to be more generous?," Experimental Economics 12, pp. 93-98.

Bhat, C. (2001), "Quasi-random maximum simulated likelihood estimation of the mixed multinomial logit model," Transportation Research B 35, pp. 677-693.

Ben-Nera, A., Kramera, A., and Levy, O. (2008), "Economic and hypothetical dictator game experiments: Incentive effects at the individual level," Journal of Socio-Economics 37, pp. 1775-1784.

Bohnet, I. and Frey, B.S. (1999), "The sound of silence in prisoner's dilemma and dictator games," Journal of Economic Behavior and Organization 38, pp. 43-57.

Bolton, G.E. and Ockenfels, A. (2000), "ERC: A theory of equity, reciprocity, and competition," American Economics Review 90, pp. 166-193.

Brañas-Garza, P. (2006), "Poverty in dictator games: Awakening solidarity," Journal of Economic Behavior and Organization 60, pp. 306-320.

Brañas-Garza, P., Cobo-Reyes, R., Paz Espinosa, M., Jiménez, N., Kováŕík J., and Ponti, G. (2010), "Altruism and social integration," Games and Economic Behavior 69, pp. 249-257.

Buchan, N.R., Johnson, E., and Croson, R.T.A. (1997), "Culture, power, and legitimacy," mimeo.

Burnham, T.C. (2003), "Engineering altruism: A theoretical and experimental investigation of anonymity and gift giving," Journal of Economic Behavior and Organization 5, pp. 133-144.

Carlsson, F., Daruvala, D., and Johansson-Stenman, O. (2005), "Are people inequality-averse, or just risk-averse?," Economica 72, pp. 375-396.

Charness, G. and Gneezy, U. (2008), "What's in a name? Anonymity and social distance in dictator and ultimatum games," Journal of Economic Behavior and Organization 68, pp. 29-35.

Dufwenberg, M. and Muren, A. (2006), " Generosity, anonymity, gender," Journal of Economic Behavior and Organization 61, pp. 42-49.

Engel, C. (2010), "Dictator games: A meta study," Preprints of the Max Plank Institute for Research on Collective Goods.

Fehr, E. and Schmidt, K.M. (1999), "A theory of fairness, competition, and 
cooperation," Quarterly Journal of Economics 114, pp. 817-868.

Forsythe, R., Horowitz, J.L., Savin, N.E., and Sefton, M. (1994), "Fairness in simple bargaining experiments," Games and Economic Behavior 6, pp. 347-369.

Goeree, J., McConnell, M., Mitchell, T., Tromp, T., Yariv, L. (2010), "The 1/d Law of giving," American Economic Journal: Microeconomics 2, pp. 183-203.

Gowdy, J.M. and Polimeni, R.I. (2005), "The death of homo economicus: Is there life after welfare economics?," International Journal of Social Economics 32, pp. 924-938.

Halton, J. (1960), "On the efficiency of evaluating certain quasi-random sequences of points in evaluating multi-dimensional integrals," Numerische Mathematik 2, pp. 84-90.

Hoffman, E., McCabe, K., Shachat, K., and Smith, V.L. (1994), "Preferences, property rights, and anonymity in bargaining games," Games and Economic Behavior 7, pp. 346-380.

Hoffman, E., McCabe, K., and Smith, V.L. (1996), "Social distance and other-regarding behavior in dictator games," American Economic Review 86, pp. 653-660.

Johannesson, M. and Persson, B. (2000), "Non-reciprocal altruism in dictator games," Economics Letters 69, pp. 137-142.

Jones, B. and Rachlin, H. (2006), "Social discounting," Psychological Science 17, pp. 283-286.

Jones, B. and Rachlin, H. (2009), "Delay, probability, and social discounting in A public goods game," Journal of Experimental Analysis of Behavior 91, pp. 61-73.

Kovarik, J. (2008), "Giving it now or later: Altruism and discounting," mimeo.

Leider, S., Mobius, M., Rosenblat, T., and Quoc-Anh, D. (2009), "Directed altruism and enforced reciprocity in social networks," Quarterly Journal of Economics 124, pp. $1815-1851$.

Louviere, J.J., Hensher, D. A., and Swait, J. D. (2000) Stated Choice Methods, Cambridge University Press.

Rachlin, H. and Jones, B.A. (2008a), "Social discounting and delay discounting," Journal of Behavioral Decision Making 21, pp. 29-43.

Rachlin, H. and Jones, B.A. (2008b), "Altruism among relatives and non-relatives," Behavioural Processes 79, pp. 120-123.

Rankin, F. W. (2006), "Requests and social distance in dictator games," Journal of 
Economic Behavior and Organization 60, pp. 27-36.

Rotemberg J.J. (2008), "Minimally altruistic wages and unemployment in a matching model with monopsony," Journal of Monetary Economics 55, pp. 97-110.

Roth, A.E., Prasnikar, V., Okuno-Fujiwara, M., and Zamir, S. (1991), "Bargaining and market behavior in Jerusalem, Ljubljana, Pittsburgh, and Tokyo: An experimental study," American Economic Review 81, pp. 1068-1095.

Sefton, M. (1992), "Incentives in simple bargaining games," Journal of Economic Psychology 13, pp. 263-276.

Takahashi, T. (2005), "Loss of self-control in intertemporal choice may be attributable to logarithmic time-perception," Medical Hypotheses 65, pp. 691-693.

Train, K.E. (2003), Discrete Choice Methods with Simulation, Cambridge University Press.

Wichardt, P.C. (2009), "A status-based motivation for behavioral altruism," International Journal of Social Economics 36, pp. 869-887.

Yamamori, T., Kato, K., Kawagoe, T., and Matsui, A. (2008), "Voice matters in a dictator game," Experimental Economics 11, pp. 336-343. 
Fig. 1: Dictator game with social discounting

Social distance and average offer rate

$\diamond$ Oneself $\square$ Family $\Delta$ Friend $\mathbf{X}$ Acquaintance $\mathbf{\mathbf { W }}$ Stranger

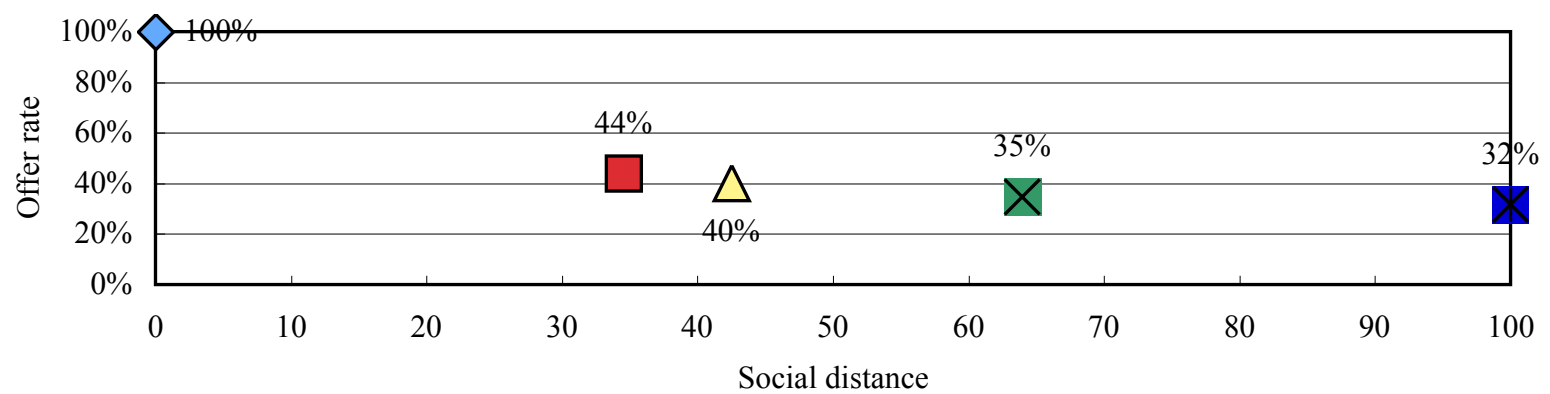

Social distance and zero offer proportion

$\diamond$ Oneself $\square$ Family $\Delta$ Friend $\mathbf{X}$ Acquaintance $\mathbf{m}$ Stranger

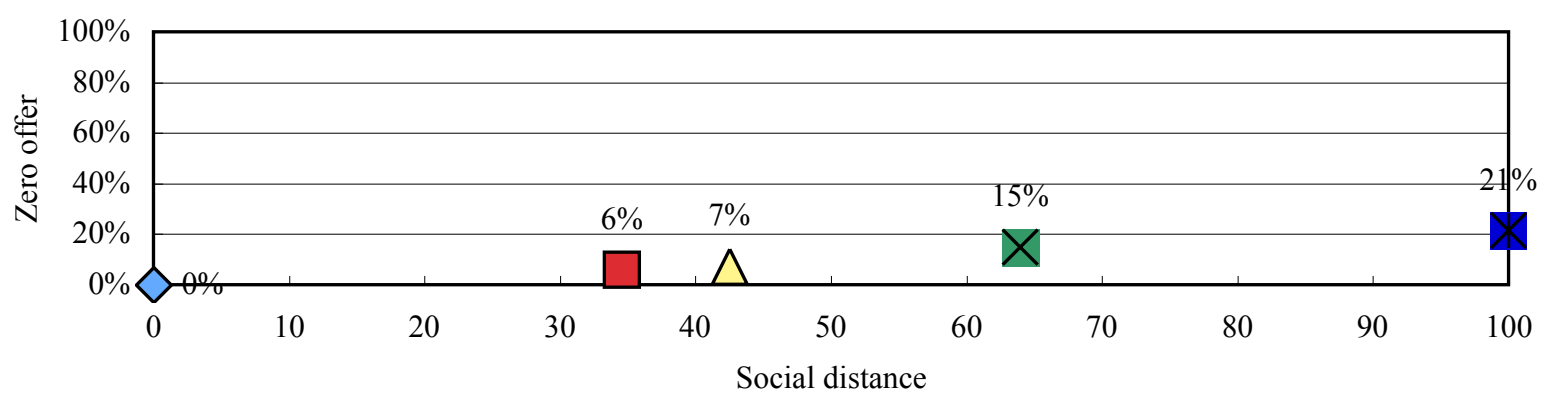

Social distance and equal offer proportion

$\diamond$ Oneself $\square$ Family $\Delta$ Friend $\mathbf{X}$ Acquaintance $\mathbf{\mathbf { m }}$ Stranger

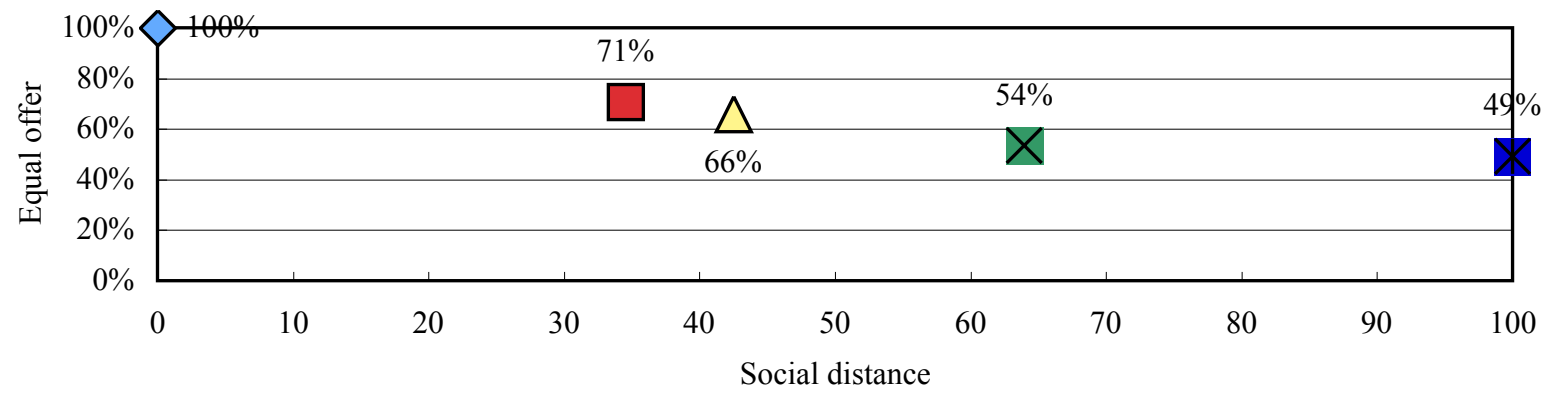


Fig. 2: Representative questionnaire

\begin{tabular}{|c|c|c|}
\hline & ALTERNATIVE 1 & ALTERNATIVE 2 \\
\hline Own payoff & $80,000 \mathrm{JPY}$ & $50,000 \mathrm{JPY}$ \\
\hline Opponent's payoff & 20,000 JPY & $50,000 \mathrm{JPY}$ \\
\hline Opponent's social distance & Stranger & Family \\
\hline Opponent's time delay & 1 year later & Now \\
\hline Choose one & & \\
\hline
\end{tabular}




\section{Table 1: Estimation results}

$\begin{array}{cc}\text { Log likelihood function } & -11866 \\ \text { Restricted log likelihood } & -14939 \\ \text { McFadden Pseudo R-squared } & 0.2057 \\ \text { RPL model with panel } & 1347 * 16\end{array}$

\begin{tabular}{|c|c|c|c|}
\hline \multicolumn{4}{|c|}{ Mean estimates } \\
\hline & Estimates & S.E. & $t$ value \\
\hline Inequality aversion rate & 0.4447 & 0.0540 & $-8.24^{* *}$ \\
\hline Social discount rate & 0.0132 & 0.0006 & $-21.49^{* *}$ \\
\hline Time discount rate & 0.0034 & 0.0001 & $-35.80^{* *}$ \\
\hline \multicolumn{4}{|c|}{ Standard deviation estimates } \\
\hline & Estimates & S.E. & $t$ value \\
\hline Inequality aversion rate & 1.7763 & 0.0544 & $32.65^{* *}$ \\
\hline Social discount rate & 0.0136 & 0.0008 & $18.00^{* *}$ \\
\hline Time discount rate & 0.0016 & 0.0001 & $11.06^{* *}$ \\
\hline
\end{tabular}

Note: ${ }^{*} \mathrm{p}<0.01,{ }^{*} \mathrm{p}<0.05$ 
Fig. 3: Tradeoff between time delay and Social distance

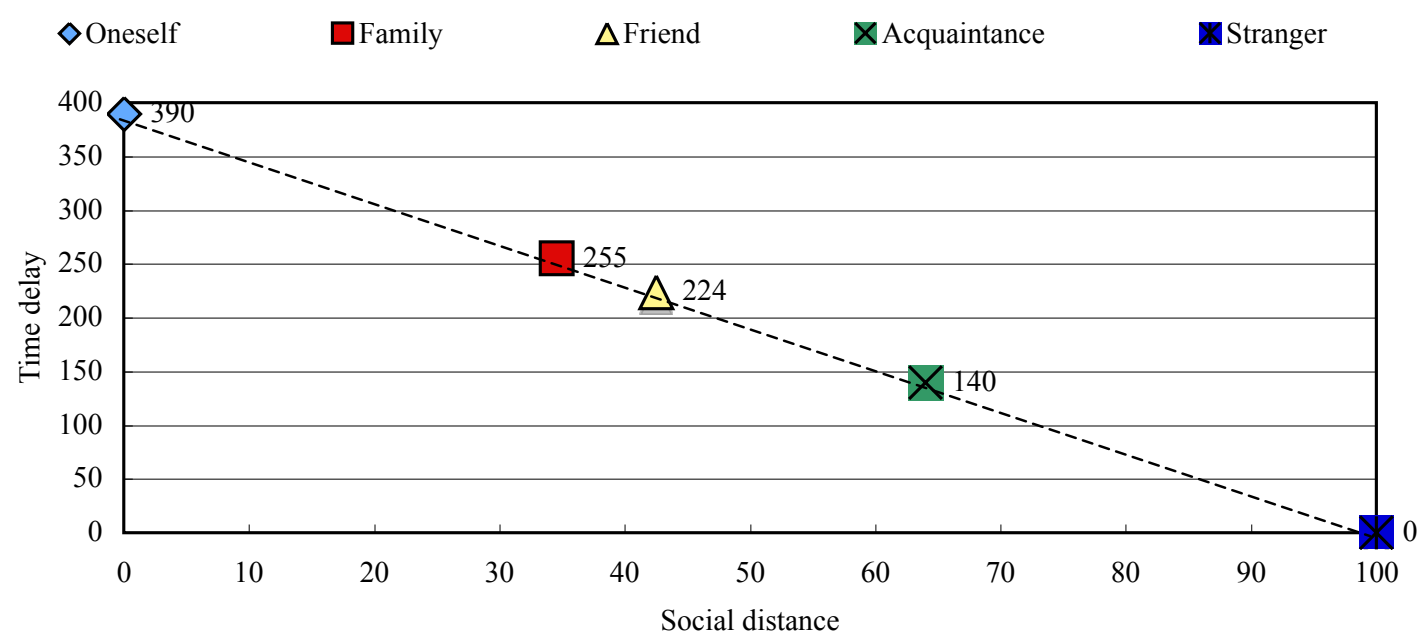


Table2: Correlations of social preferences

\begin{tabular}{cccc} 
& Inequality aversion rate & Social discount rate & Time discount rate \\
\cline { 2 - 4 } Inequality aversion rate & 1 & $-0.073(0.007)^{* *}$ & $0.247(0.000)^{* *}$ \\
Social discount rate & $-0.073(0.007)^{* *}$ & 1 & $0.086(0.002)^{* *}$ \\
Time discount rate & $0.247(0.000)^{* *}$ & $0.086(0.002)^{* *}$ & 1 \\
\hline
\end{tabular}

Note: $* * \mathrm{p}<0.01, * \mathrm{p}<0.05$ (standard errors in parenthesis) 
Table 3: Regression results of social preferences on individual characteristics

\begin{tabular}{|c|cc:cc:cc|}
\hline Explained variables & Inequality aversion rate & Social discount rate & Time discount rate \\
\hline R squared & \multicolumn{2}{|c|}{0.09} & & 0.05 & & 0.02 \\
\hline Explanatory variables & Estimates & $t$ value & Estimates & $t$ value & Estimates & $t$ value \\
\hline Constant & 0.0563 & 0.248 & 0.0138 & $11.674^{* *}$ & 0.0029 & $28.028^{* *}$ \\
Female dummy & 0.2057 & $2.331^{*}$ & -0.0002 & -0.403 & 0.0001 & $2.359^{*}$ \\
Age & 0.0094 & $2.265^{*}$ & 0.000004 & 1.806 & 0.000001 & $3.609^{* *}$ \\
Marriage dummy & -0.1890 & -1.663 & -0.0005 & -0.872 & 0.0000 & -0.362 \\
No. of children & 0.0184 & 0.342 & -0.0003 & -1.159 & 0.0000 & 1.028 \\
Education & -0.0018 & -0.282 & 0.0000 & 1.362 & 0.0000 & 0.219 \\
Household income & 0.0000 & -0.289 & 0.0000 & -0.503 & 0.0000 & -0.378 \\
\hline
\end{tabular}

Note: ${ }^{*}$ p $<0.01, * p<0.05$ 